\title{
Surveillance Colonoscopy after Polypectomy: Actual Practice in Korea
}

\author{
Kyeong Ok Kim \\ Division of Gastroenterology and Hepatology, Department of Internal Medicine, Yeungnam University College of Medicine, Daegu, Korea
}

Screening programs for colorectal cancer can decrease the mortality associated with colorectal cancer, and colonoscopy with polypectomy has been generally considered to be the most effective method of cancer prevention. ${ }^{1-3}$ Recent studies have shown that surveillance colonoscopy after polypectomy constitutes a considerable proportion of the total number of colonoscopy procedures. Although many guidelines on postpolypectomy surveillance have been introduced ${ }^{1-4}$ these have not yet been perfected owing to the several problems including confusion in pathological classification. ${ }^{5}$ According to the Vienna classification-which represents the Western system of classifying high-grade dysplasias-carcinoma in situ and intramucosal cancer can be grouped in the same category because distinction between these subcategories is irrelevant from a therapeutic viewpoint. ${ }^{6}$ However, in Korea, the consensus among pathologists is that they are distinct from each other. ${ }^{7}$ This difference in concepts can cause confusion among clinicians in Korea. From this standpoint, the study by Hong et al. was significant because it revealed the actual surveillance practices in Korea. According to Korean guidelines, the first follow-up endoscopy recommended for high-grade dysplasias is after 3 years, and there is no mention of carcinoma in situ or intramucosal cancer. ${ }^{4}$ In addition, a large proportion of clinicians do not follow the guidelines even if they work in a university hospital. ${ }^{8}$ The results showed that $32.9 \%$ of the patients with high-grade dysplasias/carcinoma in situ and intramucosal carcinoma underwent followup endoscopy within 3 months after polypectomy. The recent mean follow-up period for advanced neoplasia was at 8

Received December 20, 2013. Revised December 23, 2013

Accepted December 23, 2013.

Correspondence to Kyeong Ok Kim, Division of Gastroenterology and Hepatology, Department of Internal Medicine, Yeungnam University College of Medicine, 170 Hyeonchung-ro, Nam-gu, Daegu 705-703, Korea. Tel: +8253-620-3835, Fax:+82-53-654-8386,E-mail: cello7727@naver.com

Financial support: None. Conflict of interest: None. months. ${ }^{8}$ Considering that the guidelines suggest a follow-up at 3 years, this is too short interval between procedure and follow-up colonoscopy. Even with low-risk adenoma, several Western studies have also reported a shorter follow-up interval than that recommended in the guidelines. ${ }^{9-11}$

Several issues remain unsolved in the present study and need further clarification. First, as the authors stated, pathologists in Korea tend to report, high-grade dysplasia, carcinoma in situ, and intramucosal carcinoma as separate entities. However, the guidelines are mostly based on Western data. For an exact understanding of actual clinical practice, it is necessary to determine the clinical characteristics and followup interval for each pathology group. There is a discrepancy between pathological classification and management in Korea. In fact, many clinicians might consider that carcinoma in situ and high-grade dysplasia should be managed using different approaches. Second, before educating clinicians about guidelines, it is necessary to ensure that these guidelines are truly safe and ideal. No study has yet examined whether follow-up intervals should be identical among the subgroups. In addition, lymph node metastasis has been reported after resection of intramucosal carcoma, ${ }^{12}$ so many clinicians in Korea have been confused about the length of the follow-up interval. These results suggest the requirement of safer and more efficient guidelines, which reflect the actual situation in clinical practice.

Third, to educate clinicians, Hong et al. need to examine the cause and background of actual clinical practice in Korea in more depth. The authors describe how the heightened interest in colorectal polyps made clinicians more concerned about their recurrence. Because of this, the follow-up interval became shorter, especially in cases of advanced neoplasia. ${ }^{8}$ Furthermore, although there is no possibility of lymph node metastasis, the management and follow-up of early gastric carcinoma could affect that of intramucosal carcinoma of the colorectum. There may be several other reasons for performing aggressive surveillance irrespective of the pathological

๑ Copyright 2014. Korean Association for the Study of Intestinal Diseases. All rights reserved.

This is an Open Access article distributed under the terms of the Creative Commons Attribution Non-Commercial License (http://creativecommons.org/licenses/by-nc/3.0)

which permits unrestricted non-commercial use, distribution, and reproduction in any medium, provided the original work is properly cited. 
classification. The follow-up interval may be affected by polyp size, polyp number, degree of dysplasia, preparation status of the bowel, risk factors of colorectal cancer such as family history, and presence or absence of complete removal of the polyps. ${ }^{13}$ Determining the factors that are modifiable may help reduce the gap between guidelines and actual practice.

Despite retrospective design and several unanswered questions, the present study is very important because it is multicentric and shows the degree of understanding of the gastroenterologist in the pathology of colonic intraepithelial neoplasia and the discrepancy between guidelines and actual practice. These results indicate that a conscious effort is required to establish surveillance guidelines based on Korean data so that clinicians can be educated to adhere to these guidelines and the modifiable risk factor of over-surveillance can be reduced.

\section{REFERENCES}

1. Levin B, Lieberman DA, McFarland B, et al. Screening and surveillance for the early detection of colorectal cancer and adenomatous polyps, 2008: a joint guideline from the American Cancer Society, the US Multi-Society Task Force on Colorectal Cancer, and the American College of Radiology. CA Cancer J Clin 2008;58:130-160.

2. Rex DK, Johnson DA, Anderson JC, Schoenfeld PS, Burke CA, Inadomi JM. American College of Gastroenterology guidelines for colorectal cancer screening 2009 [corrected]. Am J Gastroenterol 2009;104:739-750.

3. Arditi C, Peytremann-Bridevaux I, Burnand B, et al. Appropriateness of colonoscopy in Europe (EPAGE II). Screening for colorectal cancer. Endoscopy 2009;41:200-208.

4. Yang DH, Hong SN, Kim YH, et al. Korean guidelines for post- polypectomy colonoscopic surveillance. Intest Res 2012;10:89109.

5. Schlemper RJ, Kato Y, Stolte M. Review of histological classifications of gastrointestinal epithelial neoplasia: differences in diagnosis of early carcinomas between Japanese and Western pathologists. J Gastroenterol 2001;36:445-456.

6. Schlemper RJ, Kato Y, Stolte M. Diagnostic criteria for gastrointestinal carcinomas in Japan and Western countries: proposal for a new classification system of gastrointestinal epithelial neoplasia. J Gastroenterol Hepatol 2000;15(Suppl):G49-G57.

7. Chang HJ, Park CK, Kim WH, et al. A standardized pathology report for colorectal cancer. Korean J Pathol 2006;40:193-203.

8. Hong SP, Kim TI, Kim HG, et al. Clinical practice of surveillance colonoscopy according to the classification of colorectal intraepithelial neoplasia in Korea: high-grade dysplasia/carcinoma in situ versus intramucosal carcinoma. Intest Res 2013;11:276-282.

9. Mysliwiec PA, Brown ML, Klabunde CN, Ransohoff DF. Are physicians doing too much colonoscopy? A national survey of colorectal surveillance after polypectomy. Ann Intern Med 2004;141:264-271.

10. Boolchand V, Olds G, Singh J, Singh P, Chak A, Cooper GS. Colorectal screening after polypectomy: a national survey study of primary care physicians. Ann Intern Med 2006;145:654-659.

11. Schoen RE, Pinsky PF, Weissfeld JL, et al. Utilization of surveillance colonoscopy in community practice. Gastroenterology 2010;138:73-81.

12. Kim HY, Ko BM, Kwon KW, et al. A case of recurrent cancer after endoscopic resection for colorectal mucosal cancer. Intest Res 2003;1:201-210.

13. Ransohoff DF, Yankaskas B, Gizlice Z, Gangarosa L. Recommendations for post-polypectomy surveillance in community practice. Dig Dis Sci 2011;56:2623-2630. 